\title{
Aerosol delivery systems for bronchial asthma
}

\author{
PL Ariyananda, JE Agnew, SW Clarke
}

\begin{abstract}
Summary
Many different inhalation devices are now available for the treatment of asthma. Pressures towards the elimination of chlorofluorocarbon propellants are driving forward development of new devices - as are obvious commercial pressures, including the increased availability of generic formulations. We still, however, often cannot tell exactly where within the lung we want to target a particular medication, be it a bronchodilator or a steroid. The basic processes of aerosol deposition are readily comprehensible. Nevertheless, even under carefully supervised inhalation conditions, one can only roughly estimate where the medication is deposited. We can, however, hope to give our patients good guidance on how to make the best use of a metered-dose inhaler or a jet nebuliser. From the array of available devices, we will increasingly be able to select the most comfortable and convenient for the patient - and therefore most likely to encourage good compliance.
\end{abstract}

Keywords: asthma, aerosols, inhalation devices, nebulisers

Royal Free Hospital, Pond Street, London NW3 2QG, UK.

Department of Thoracic Medicine PL Ariyananda

SW Clarke

Department of Medical Physics

JE Agnew

Correspondence to Dr JE Agnew

Accepted 14 September 1995
Inhalation therapy is a remedy from ancient times, fumes from burning leaves of Datura species and even tobacco being considered as anti-asthma remedies. Inhalation of medicinal vapour became an established treatment when adrenaline was made available in the late $1920 \mathrm{~s}^{1} \mathrm{~A}$ very significant advance in the 1950 s was the introduction of the metered-dose inhaler (MDI). ${ }^{2}$

By 1980, many different inhalational devices were available and vast numbers of patients worldwide were receiving medication by inhalation. Currently the diversity of nebuliser-compressor combinations has become almost too complex to evaluate; dry powder inhalers (DPIs) are available in an increasing variety of formats and MDI manufacturers are under pressure to move away from ozone-unfriendly propellants.

\section{Physical properties of aerosols}

The enormous appeal of aerosol therapy for asthma is that it achieves targeting of the medication directly onto the lung epithelial surfaces. Often this means that the drugs can be effective in very low doses. Thus microgram quantities of a $\beta_{2}$-agonist by inhalation may produce the same bronchodilatation as milligram quantities given orally. With aerosol inhalation, patients can be spared the side effects usually associated with systemic administration.

Notable advances have occurred in analysing where receptor sites for different drugs are located within the lung. ${ }^{3}$ Images obtained with radioactively labelled drugs give some idea of their distribution within the lung.,5 Even so, little specific information is available to help the physician precisely target medication, for example, when prescribing a $\boldsymbol{\beta}_{2}$-agonist for intermittent use by the mildly asthmatic patient. It is linking together ideas of receptor sites and ideas of drug deposition which remains a difficulty. Conventional wisdom is that asthma, a 'disease of small airways', is best treated with particles of $1-5 \mu \mathrm{m}$ in diameter. ${ }^{6}$ The hope is that these particles are small enough to penetrate into the small airways yet large enough to be deposited efficiently in the relatively peripheral airways.

The efficacy of any drug inhalation therapy depends on the amount of drug deposited within the lungs. This depends on (a) physical factors such as the particle size of the drug, ${ }^{7}$ its density, ${ }^{8}$ electric charge, ${ }^{9}$ hygroscopicity, ${ }^{10}$ propellants, ${ }^{11}$ and surfactants, ${ }^{11}(b)$ the mode of inhalation such as the flow rate, ${ }^{12}$ volume of inspiration, ${ }^{13}$ degree of lung inflation at the beginning of inspiration, ${ }^{14}$ breath-holding time ${ }^{13}$ and hand-breath coordination, ${ }^{10}$ and $(c)$ the patency of the airways. ${ }^{15}$

An aerosol is a suspension of fine liquid or solid particles in air. The size of these particles should be sufficiently large not to diffuse like gas molecules and sufficiently small to remain air-borne for some time. When aerosols are inhaled, particles larger than $5 \mu \mathrm{m}$ suffer impaction in the upper airways. Particles of $2-5 \mu \mathrm{m}$ in diameter undergo impaction and gravitational sedimentation in the lungs. Submicronic particles tend to behave like gas molecules while particles of about $0.5 \mu \mathrm{m}$ are breathed in and out of the alveoli with minimal actual deposition. Currently almost all anti-asthma drugs are available in aerosol form. These include $\beta_{2}$-stimulants, steroids, antimuscarinic drugs, sodium cromoglycate and nedocromil sodium. Theophylline is not currently used because of its irritant action. ${ }^{16}$

\section{Aerosol delivery systems}

Three principal types of devices are widely used in aerosol administration, MDIs, DPIs and nebulisers. The drugs that are available in the UK for delivery via these devices are mentioned in this article. 


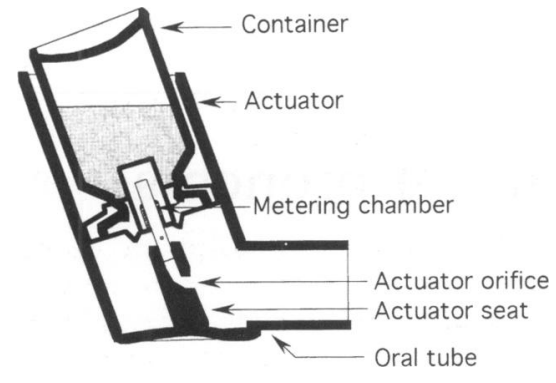

Figure 1 Pressurised metered dose inhaler (MDI)
METERED-DOSE INHALERS (MDIs)

MDIs are at present the most widely used type of aerosol delivery system. The essential components of an MDI include $(a)$ a canister containing the drug mixed with propellant and surfactant, and $(b)$ the mouth-piece that acts as the delivery conduit as well as the actuator seat for the release of the drug (figure 1).

The canister is fitted with a valve which delivers $25-100 \mu \mathrm{l}$ of its contents from a metering chamber. The propellants that are in use are chlorofluorocarbons (CFCs). CFC propellants (marketed under the trade names Freons or Arctons 11,12 and 114) are compounds in which the hydrogen atoms of methane and ethane are replaced by chlorine and fluorine. CFCs are biologically inactive and liquefy when pressurised but, on release into the atmosphere, evaporate rapidly and cause any material that is suspended or dissolved in them to be carried away at great speed in the pointed direction. The vapour pressure inside the canister is $300-500 \mathrm{kPa}$ (three to five times atmospheric pressure). With each actuation the metering chamber delivers a fixed quantity of micronised drug which is held in the canister as a suspension or in solution. As the aerosol leaves the nozzle of the canister it forms a plume of gas which flows at a rate of about $30 \mathrm{~ms}^{-1}$ (over $100 \mathrm{~km} / \mathrm{h}$ ). The aerosol that is released expands rapidly and evaporates giving rise to a cooling effect. The micronised particles are prevented from agglomerising by surfactants such as sorbitan trioleate, oleic acid and lecithin. The surfactant is responsible for the characteristic taste and the propellant causes cooling. The aerosol consists of droplets of variable size and their size shrinks rapidly on evaporation. A recent study using directly radiolabelled salbutamol has shown that about $20 \%$ of the metered dose gets deposited in the lungs with the proper inhalational technique. ${ }^{17}$

$\beta_{2}$-agonist MDIs are available containing salbutamol, terbutaline sulphate, fenoterol hydrobromide, pirbuterol, reproterol hydrochloride, rimiterol hydrochloride and salmeterol. Salmeterol has slow onset of action but its effects persist for 12 hours; it is accordingly not used for acute asthma but can be used to prevent the onset of attacks. ${ }^{18}$ Fenoterol seems to have been associated with an increase in fatal ${ }^{19,20}$ and near fatal ${ }^{21}$ attacks of asthma, although controversy remains as to the mechanisms involved. ${ }^{22}$ Steroid MDIs are available with beclomethasone dipropionate, budesonide and fluticasone propionate. Fluticasone propionate, which came to the market recently, has a high selectivity, high topical potency, poor gastrointestinal absorption and undergoes rapid first-pass metabolism in the liver. ${ }^{23}$ In severe asthma, it is more effective than beclomethasone dipropionate $\mathrm{e}^{24}$ and budesonide $\mathrm{e}^{25}$ and is almost free of side effects even when taken at a high dose over a short period. ${ }^{24,25}$ The Autohaler ${ }^{\circledR}$ is a breath-actuated MDI which is available with beclomethasone dipropionate, ipratropium bromide, salbutamol or sodium cromoglycate. High-dose beclomethasone dipropionate is available as Becloforte ${ }^{\circledR}$ and (as discussed below) should be used with a spacer device (Volumatic $\left.{ }^{\circledR}\right)$. Antimuscarinic bronchodilators such as ipratropium bromide and oxitropium bromide are also available as MDIs.

As already mentioned, the initial velocity of particles from an inhaler is very high and particles can easily be wasted if the patient does not synchronise his breath with delivery of the aerosol into the mouth. It is therefore important to instruct the patient with regard to the correct use of MDIs. ${ }^{26}$ In practice, a crucial requirement is adequate hand-breath co-ordination. A protocol for the correct use of an MDI is given in box 1 .

The patient should allow a time gap of at least $30 \mathrm{~s}$ between puffs for the metering valve to rewarm in order to provide a consistant dosage. There is a theoretical advantage to be gained from a pause of several minutes between successive doses of bronchodilator or between doses of bronchodilator and corticosteroid, in order that the first dose would have some initial bronchodilating effect, opening up partially closed airways into which the second dose might penetrate. However the evidence that this helps in actual practice is inconclusive. ${ }^{27,28}$

The amount of drug delivered by MDIs can be improved by using spacer devices. The spacer device is an attachment to the MDI which forms a reservoir from which the patient can inhale the aerosol. This is useful in patients with poor hand-breath co-ordination and has been shown to improve pulmonary deposition pattern. ${ }^{29}$ Spacers allow rapidly moving droplets to slow down and larger droplets to evaporate and reduce in size making the aerosol more suitable for inhalation. In addition, spacers help to reduce oropharyngeal deposition of the drug, and hence reduce the incidence of hoarseness of the voice and oropharyngeal candidiasis in the case of corticosteroids. Therefore their use is recommended for patients on high-dose inhaled steroids. ${ }^{30}$ For beclomethasone dipropionate inhaled using a spacer (Volumatic ${ }^{\circledR}$ ), the amount of respirable particles was shown to reduce with multiple actuations and also with prolonga- 
tion of time between actuation and inhalation. ${ }^{31}$ Spacer devices vary in size (volumes range from 120 to over $1000 \mathrm{ml}$ ) and in shape. They also vary in the valving that separates inspired from expired gas and in features such as measurement of inhaled volumes and flow rate. Another device that improves pulmonary deposition of aerosol in patients with poor hand-breath coordination is a breath-actuated device called the Autohaler ${ }^{\circledR} .^{32}$

CFCs are incriminated in the reduction of the earth's stratospheric ozone layer ${ }^{33}$, currently of great concern to all who study the earth's environment. CFCs are inert and resistant to natural degradation in the lower atmosphere. Those that are released to the atmosphere, however, slowly ascend to the stratosphere and can remain there for 40 to 150 years. Photodissociation of CFCs in the stratosphere liberates chlorine which catalyses the breakdown of ozone. Even if CFC production is stopped immediately, that which has already accumulated will go on breaking down ozone for several years. Already there is a hole in the stratospheric ozone layer over the Antarctic. ${ }^{34}$ Normally the stratospheric ozone layer prevents excess UV light reaching the earth. Excess UV light can increase the risk of skin conditions such as basal and squamous cell carcinoma, malignant melanoma, actinic kerotosis, actinic elastosis, photoaging and sunburn and ophthalmic conditions such as cataract, corneal photokeratosis, pterigium, climate droplet keratopathy, retinal damage and melanoma of the uveal tract. ${ }^{35}$

MDIs contribute only about $0.5 \%$ of the total CFCs produced in industries worldwide. The Montreal Protocol of 1987 proposed a progressive reduction in CFC use. ${ }^{33}$ In 1990 , the participating countries voted to phase out CFC production completely by the year 2000 and in 1992 this deadline was advanced to $1996 .^{33,36}$ For this reason scientists were compelled to find alternate propellants and presently two fluorocarbon compounds, HFA 134a and HFA 227, are being widely evaluated. ${ }^{36}$ Hydrofluoroalkane, HFA 134a, was found to have no adverse effects in animal experiments. ${ }^{37}$ When HFA 134a is inhaled, $99 \%$ of it is exhaled and what is absorbed is shown to have a very short half-life with no adverse effects in humans. ${ }^{38}$ Clinical studies carried out using HFA 134a formulations of salbutamol, salmeterol and fluticasone propionate have shown equivalent efficacy with a similar safety profile to the existing CFC-containing formulations at equivalent dosages. ${ }^{39}$ When non-CFC-propellant-containing MDIs come onto the market, it will be important for health professionals to maintain good communication with their patients and fully explain to them the reasons for the change. ${ }^{35}$ Non-CFC propellants should be carefully monitored even after they come to the market. ${ }^{40}$

MDIs and DPIs are generally colour-coded for easy recognition. Those that prevent asthma are brown and those that relieve asthma are blue. The advantages and disadvantages of MDIs are given in box 2 .

\section{DRY POWDER INHALERS (DPIs)}

DPIs were introduced in the 1960s. The original device contained sodium cromoglycate in a capsule and was called the Spinhaler. The Spinhaler has a breath-operated propeller which generates an air current driving out the drug powder which is liberated by piercing the capsule. In the 1970s, DPIs using $\beta_{2}$-stimulants and steroids came onto the market. In these devices the drug was loaded as a capsule containing micronized particles in a lactose carrier or spheronized or pelletised agglomerates. One such device is called the Rotahaler ${ }^{\circledR}$ and the capsules that are used, containing salbutamol or beclomethasone dipropionate, are called Rotacaps ${ }^{\circledR}$. These are single-dose inhalers where the patient has to load the capsule and puncture it just prior to use. This was rather inconvenient, but the problem was overcome with the advent of multidose inhalers. Examples of single-dose inhalers are given in figure 2.

Two types of multidose DPIs are now widely available. They are the Diskhaler $^{\circledR}$ (Allen and Hanbury) and Turbuhaler ${ }^{\circledR}$ (Astra). The Diskhaler is available with salbutamol, salmeterol, beclomethasone or fluticasone. It is a flat device that takes a disk containing eight metered doses of the drug in small blisters. The drug is contained in these blisters as microfine particles mixed in a lactose carrier. The blister is perforated just before inhalation. The Turbuhaler ${ }^{\circledR}$ can deliver 200 doses of either the $\beta_{2}$-stimulant terbutaline or the corticosteroid budesonide. The drug in this device has no additives and is present as micronized particles that are spheronized into loose aggregates of approximately $1 \mathrm{~mm}$ diameter. When the base of the Turbuhaler ${ }^{\circledR}$ is twisted relative to the barrel with the unit held vertically the drug is released from a reservoir, ready to be inhaled. When the patient inhales from the Turbuhaler ${ }^{\circledR}$ he does not feel the drug enter his mouth as there are no additives like propellants (which give the cooling of the Freon spray) or lactose (which imparts a taste). It is important that this

Figure 2 Dry powder inhaler (DPI). The direction of the air flow is shown by the arrows. Upper figure: components of a Spinhaler $^{\otimes} \cdot a=$ capsule, $b=$ fan blades, $c=$ piercing needles, $\mathrm{d}=$ meter casing, $\mathrm{e}=$ inner casing. Lower figure: components of a Rotahaler $^{\circledR}$. $f=$ capsule, $g=$ outer casing, $h=$ inner casing. With permission from $^{7}$ 


\begin{tabular}{|l|}
\hline Dry-powder inhalers \\
\hline Advantages \\
- light \\
- quick delivery of drugs \\
require no hand-breath \\
- contination \\
Disadvantages \\
- expensive \\
- require high inspiratory flow \\
only available with few anti-asthma \\
\hline
\end{tabular}

Box 3

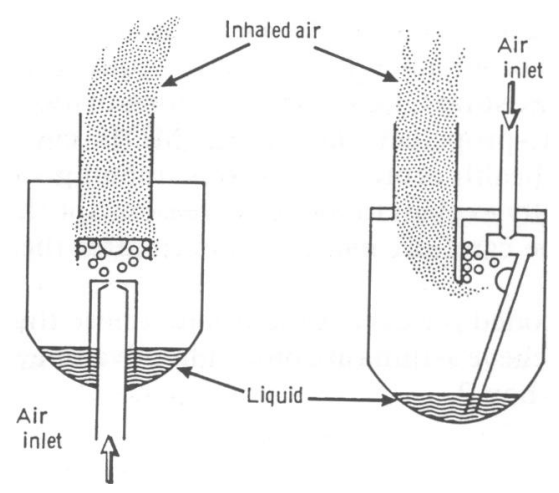

Figure 3 Two different designs of the jet nebuliser. Liquid is drawn up a feed tube by a stream of compressed gas. The liquid fragments into droplets. Larger droplets impinge on the baffles and the smaller droplets are carried away on the inhaled air stream. With permission from ${ }^{7}$

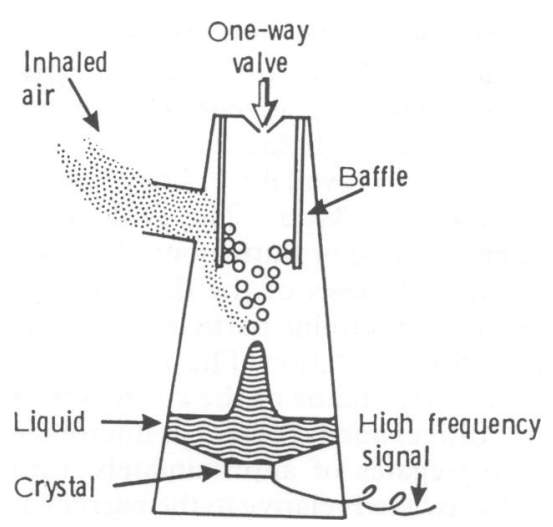

Figure 4 Ultrasonic nebuliser. Vibration of a piezoelectric crystal causes formation of large and small droplets. With permission from $^{7}$ information should be given to the patient to avoid any inadvertent repetition of the dose.

When DPIs are used the patient should be instructed to $(a)$ take a rapid deep breath and to hold it as long as possible and $(b)$ to breathe out after taking the mouth away from the inhaler. Breathing into the device can cause dispersion of drug within it as well as clumping of drug particles due to moisture from exhaled breath. The main advantages and disadvantages of DPIs are given in box $3 .^{41} \mathrm{~A}$ recent study shows that when budesonide is inhaled via a Turbuhaler ${ }^{\circledR}$, pulmonary deposition is double that obtained with an MDI. ${ }^{42}$ It has also been shown that terbutaline delivered by Turbuhaler $^{\circledR}$ is as effective as salbutamol delivered by $\mathrm{MDI}$ in a group of patients living in hot humid regions. ${ }^{43} \mathrm{~A}$ comparative study of terbutaline and placebo from a pressurised MDI and DPI showed that the additives of the MDIs may cause bronchoconstriction in some patients with asthma. ${ }^{44}$

\section{NEBULISERS}

The other type of delivery system that is widely used is the nebuliser. There are two types of nebulisers, namely jet nebulisers and ultrasonic nebulisers. Examples are shown in figures 3 and 4.

Jet nebulisers are more commonly used; they work on a stream of compressed air or oxygen that is forced through a narrow tube which lies just above the surface of the fluid to be nebulised. The liquid gets drawn up by the Venturi effect and is fragmented into droplets by the high-velocity jet of air. The droplets vary in size and the rate of aerosol production is proportional to the velocity of the jet of air. The ideal flow rate is about $81 / \mathrm{min}$. Large droplets impact on the baffles near the orifice of the jet and fall back into the reservoir. Although the fill volume recommended for satisfactory nebulising was in the past $4-6 \mathrm{ml},{ }^{45}$ recent work with new nebuliser designs has shown a fill volume of $2.5 \mathrm{ml}$ to be adequate with some nebulisers. ${ }^{46}$ The time taken to nebulise this amount of liquid is about 10 to 15 minutes. It is obviously desirable to keep the duration of nebulisation below 10 minutes as longer durations are associated with poor compliance. During nebulisation only about $10 \%$ of the drug is delivered to the lungs and about $80 \%$ gets trapped in the reservoir, tubing and mask; the rest is exhaled.

In the ultrasonic nebuliser the energy required for production of aerosol is derived from vibrations produced by a piezoelectric crystal. ${ }^{47}$ These nebulisers generate minimal noise and the solution being nebulised gradually gets warmer. The higher incidence of cough during nebulising with an ultrasonic nebuliser compared to a jet nebuliser is thought to be due to greater impaction of the aerosol in the oropharynx. ${ }^{48}$ The particle size of aerosols generated by ultrasonic nebulisers is larger than those from jet nebulisers. Drugs that are available in suspension for nebulisation are shown in box 4 .

Nebulisers can be used for a wide range of patients such as those with severe asthma, chronic asthma not stabilised with other treatments, and severe chronic obstructive airways disease. They also have a valuable role for those old and young patients who cannot cope with other inhaler devices. Nebulisers are bulky and the treatment is time consuming and therefore it is mostly used in hospital practice. It is worth mentioning that even slow vital capacity inhalations with nebulisers have given good pulmonary deposition patterns. ${ }^{49}$ In the recent past, home use of nebulisers has increased enabling some reduction in hospital admissions. Portable nebulisers which make use of power from a rechargeable battery pack or from a car cigarette lighter socket are now available. Conventional nebulisers produce aerosols continuously; this results in wastage of the aerosol and contamination of the environment. ${ }^{50}$ These undesirable effects can be minimised by delivering the aerosol only during the phase of inspiration by using a set of valves. Such a change enhances the effective output of nebulisers. The conventional nebuliser produces a constant flow of gas which is driven through the drug chamber and air from outside does not get drawn in. The 'open vent' type of nebulisers that have come to the market recently allow air to be drawn in during the inspiratory phase and this facilitates greater aerosol production and reduction in particle size thereby cutting down the nebulising time. ${ }^{51,52}$ The advantages and disadvantages of the two types of nebulisers are given in boxes 5 and 6.

\section{Aerosol therapy in children}

Aerosol therapy is very useful in the management of childhood asthma but the mode of administration is determined to a great extent by the age of the child. Nebulised aerosols can be given to children and most children over the age of seven years can be trained to use MDIs and DPIs. Children between about four and seven years can be trained to use a DPI or a MDI with a spacer, but most 


\begin{tabular}{|l|}
\hline $\begin{array}{l}\text { Drugs available in } \\
\text { suspension for nebulisation }\end{array}$ \\
\hline - $\beta_{2}$ adrenoceptor agonists: \\
salbutamol, terbutaline sulphate, \\
fenoterol hydrobromide \\
- antimuscarinic drugs: ipratropium \\
bromide \\
- steroids: budesonide \\
- sodium cromoglycate \\
\hline
\end{tabular}

Box 4

\begin{tabular}{|l|}
\hline Jet nebulisers \\
\hline Advantages \\
- high output of aerosol \\
- can inhale with tidal breathing \\
- can administer a mixture of drugs \\
Disadvantages \\
- bulky \\
- require a power source \\
- high initial cost \\
- cooisy operation \\
\hline
\end{tabular}

Box 5

\begin{tabular}{|l|}
\hline Ultrasonic nebulisers \\
\hline Advantages \\
- can inhale with tidal breathing \\
- can give a mixture of drugs \\
Disadvantages \\
- require a power source \\
- more expensive \\
- take longer time to deliver drugs \\
\hline
\end{tabular}

Box 6

1 Newman SP, Clarke SW. Inhalation devices and techniques. In: Clark TJH, Godfrey S, Lee TH eds. Asthma. London: Chapman and Hall, 1992; pp 469-505.

2 Freedman T. Medihaler therapy for bronchial asthma: a new type of aerosol therapy. Postgrad Med F 1956; 20: 667-73.

3 Barnes PJ. Neural mechanisms in asthma. $\mathrm{Br}$ Med Bull 1992; 48: 149-68.

4 Newman SP, Clark AR, Talaee N, Clarke SW. Pressurised aerosol deposition in the human Pressurised aerosol deposition in the human
lung with and without an 'open' spacer device. lung with and without an

5 Newman SP, Moren F, Trofast E, Talaee N, Clarke SW. Deposition and clinical efficacy of terbutaline sulphate from Turbuhaler, a new multi-dose powder inhaler. Eur Respir f 1989; 2: 247-52.

6 Nebulisers. British National Formulary 1994; 27: 119-21.

7 Newman SP. Production of radioaerosols. In: Clarke SW, Pavia D, eds. Aerosols and the lung. London: Butterworths, 1984; pp 71-91.

8 Stuart BO. Deposition of inhaled aerosols. Arch Intern Med 1973; 131: 60-3.

9 Hashish AH. Selective deposition of pulsed aerosols in the human lung. $\mathcal{F}$ Aerosol Sci 1992; 23 (suppl 1): 473-6.

10 Porstendorfer J, Gebhart J, Robig G. Effect of evaporation on the size distribution of nebulized evaporation on the size distribution of
aerosols. $\mathcal{J}$ Aerosol Sci 1977; 8: 371 .

11 Hayton WL. Propellent-powered nebulizers. $f$ Am Pharm Assoc 1976; 16: 201.

children between 18 months and four years find MDIs and DPIs too difficult to handle.

The main mode of administration to children below the age of 18 months is by a nebuliser. In this age group the response to $\beta_{2}$-agonists is not as good as in older children; this is thought to be due to relative insensitivity of $\beta_{2}$-receptors and the smooth muscles found in smaller airways. $\beta_{2}$-agonists can be administered to children of this age group via an MDI secured through a hole at the bottom of a paper coffee cup with the rim held loosely over the face and with this improvised applicator about 10 puffs of $\beta_{2}$-agonist are recommended, to be given with an interval of 10 seconds between each puff. A baby-spacer device (Babyhaler ${ }^{\circledR}$ ) has been used successfully to administer salbutamol from an MDI to infants. ${ }^{53}$

Nebuliser therapy should be carried over a period of five to 10 minutes as children cannot be expected to cooperate for a longer period. It is important to see that the child gets the nebulised aerosol continuously to gain maximum benefit. When $\beta_{2}$-agonists are administered by parents or carers for acute asthma at home, if there is no satisfactory response within a few minutes or if the attack recurs in an hour or two, medical advice should be sought. As children can tolerate several times the nebulised dose of $\beta_{2}$-agonist orally, overdosing from aerosol inhalation is an unlikely occurrence. As it is difficult to keep a count of puffs, DPIs such as the Rotahaler $^{\circledR}$ or the Diskhaler ${ }^{\circledR}$ are preferred to MDIs in children.

\section{Future prospects}

As 1996 approaches and CFCs are being phased out, new developments such as hydrocarbon propellants and different types of MDIs are coming into the picture. In addition, an increasing number of non-proprietary formulations of salbutamol and beclomethasone dipropionate are now marketed with little formal demonstration of their equipotency.$^{54,55}$ The important considerations for future use include adequate testing of equipotency of generic formulations and the efficacy of different nebuliser-compressor combinations. ${ }^{47}$

A mechanical microspray pump capable of delivering aqueous solutions to the respiratory tract is being developed.$^{56}$ Another innovation is the Respimat where aerosol is generated by a piezoelectric effect. ${ }^{57} \mathrm{~A}$ device called the Dynamic Powder Dispenser which actively insufflates the drug powder into the mouth is being developed. ${ }^{58} \mathrm{~A}$ tape-based powdered inhaler which works with a breathactuated hammer is also being developed. ${ }^{59}$ DPIs should be improved so that they are effective even at low inspiratory flow rates. When liposomes containing sodium cromoglycate were given by jet nebuliser detectable levels of the drug were found even up to 25 hours later. ${ }^{60}$ When an equivalent dose of sodium cromoglycate was given as nebulised solution the drug was not detectable in blood after 25 hours. This shows that there is a potential for the use of anti-asthma drugs as nebulised liposome particles. As these new innovations and adjustments will take time, the pharmaceutical industry has recently been given a period of grace to use CFCs exclusively for MDIs.

12 Dolovich MB, Ruffin RE, Roberts R, Newhouse MT. Optimal delivery of aerosols from metered dose inhalers. Chest 1981; 80 (suppl): 911.

13 Newman SP, Pavia D, Garland N, Clarke SW. Effects of various inhalation modes on the deposition of radioactive aerosols. Eur $f$ Respir Dis 1982; 63 (suppl): 57-65.

14 Newhouse MT, Ruffin R. Deposition and fate of aerosolized drugs. Chest 1978; 73: 936-43.

15 Pavia D, Thomson ML, Shannon HS. The Pavia D, Thomson ML, Shannon HS. The
effect of airway obstruction and tidal volume of aerosol inhaled on the depth of deposition in the aerosol inhaled on the depth of deposition in the human

16 Cushley MJ, Holgate ST. Efficacy of inhaled methylxanthines as bronchodilators in asthma. Thorax 1983; 38: 223.

17 Melchor R, Biddiscombe MF, Mack VH, Short MD, Spiro SG. Lung deposition patterns of directly labelled salbutamol in normal subjects and in patients with reversible airflow obstruction. Thorax 1993; 48: 506-11.

18 Salmeterol xinafoate. In: Reynolds, JEF, ed Martindale. The extra phamacopoeia. 1993; London: The Pharmaceutical Press, 1993; p London:

19 Crane J, Pearce NE, Flatt A, et al. Prescribed fenoterol and death from asthma in New Zealand, 1981-83: case controlled in study. Lancet land, 1981-83:

20 Pearce N, Beasely R, Crane J, Burgess C, Jackson R. End of the New Zealand asthma mortality epidemic. Lancet 1995; 345: 41-4.
21 Burgess C, Pearce N, Thiruchelvam R, et al. Prescribed drug therapy and near fatal asthma attacks. Eur Respir f 1994; 7: 498-503.

22 Blauw GJ, Westendorp J. Asthma deaths in New Zealand: whodunnit? (commentary) Lancet 1995; 345: 2-3.

23 Harding SM. The human pharmacology of fluticasone propionate. Respir Med 1990;84 (suppl A): 25-9.

24 Barnes NC, Marone G, Di Maria GU, Visser S, Utama I, Payne SL. Comparison of fluticasone propionate $1 \mathrm{mg}$ daily with beclomethasone dipropionate $2 \mathrm{mg}$ daily in the treatment of severe asthma. Eur Respir F 1993; 6: 877-84.

25 Ayres JG, Harris TAJ, Bateman ED, Lundback B. The effects of fluticasone propionate $1 \mathrm{mg}$ and $2 \mathrm{mg}$ daily, and budesonide $1.6 \mathrm{mg}$ daily in severe asthmatics. Thorax 1994; 49: 403.

26 Newman SP. Therapeutic aerosols. In: Clarke SW, Pavia D, eds. Aerosols and the lung. London: Butterworths, 1984; pp 197-224.

27 Riley DJ, Liu RT, Edelman NH. Enhanced responses to aerosolized bronchodilator therapy in asthma using respiratory manoeuvres. Chest in asthma using rest

28 Lawford P, McKenzie D. Pressurised aerosol inhaler technique: how important are the inhalations from residual volume, inspiratory flow rate and time interval between puffs? $\mathrm{Br} \mathcal{F}$ Dis Chest 1983; 77: 276-81. 
29 Hindle M, Chrystyn H. Relative bioavailability of salbutamol to the lung following inhalation using metered dose inhalation methods and spacer devices. Thorax 1994; 49: 549-53.

30 British Thoracic Society, Research unit of Royal College of London, King's Fund Centre, National Asthma Campaign. Guidelines for management of asthma in adults. I. Chronic management of asthma in adults. I. Chro

31 O'Callaghan C, Cant M, Robertson C. Delivery of beclomethasone dipropionate from a space device: what dose is available for inhalation? Thorax 1994; 49: 961-4.

32 Newman SP, Weisz AW, Talaee N, Clarke SW Improvement of drug delivery with a breath actuated pressurised aerosol for patients with poor inhaler technique. Thorax 1991; 46: 712-6.

33 Hauck HR. Do medical CFCs threaten the environment? f Aerosol Med 1991; 4: 169-74.

34 Farman JC, Gardiner BG, Shaklin JD. Large losses of ozone in Antarctica reveal seasonal $\mathrm{ClO}_{2} / \mathrm{NO}_{2}$ interaction. Nature 1985; 315: 207-10.

35 Partridge MR. Metered-dose inhalers and CFCs: what respiratory physicians need to CFCs: what respiratory physicians need know. Respir Med 1994; 88: 645-7.

6 Leach CL. Approaches and challenges to use Freon propellant replacements. F Aerosol Med 1993; 6: 231 .

37 Alexander DJ. Safety of propellants. $\mathcal{F}$ Aerosol Med 1995; 8 (suppl 1): S29-S34.

38 Ventresca GP. Clinical pharmacology of HFA 134a. F Aerosol Med 1995; 8 (suppl 1): S35-S39.

39 Jenkins M. Clinical evaluation of CFC-free metered dose inhalers. 7 Aerosol Med 1995; 8 (suppl 1): S41-S47.

40 Replacement of chlorofluorocarbons in metered dose inhalation products. Note of Guidance. Commission of European Communities. III/5462/ 93-Final.

41 Dolovich MB, Vanzielegham M, Hidinger KG, Newhouse MT. Influence of inspiratory flow rate on the response to terbutaline sulphate rate on the response to terbutaline sulphate
inhaled via the Turbuhaler ${ }^{8}$. Am Rev Respir Dis 1988; 137: A433.
42 Thorssan L, Edsbacker S, Condrason T-B. Lung deposition of budesonide from Turbuhaler is twice that from a pressurised metered dose inhaler P-MDI Eur Respir $71994 ; 7$ 1839-44.

43 Lindsay DA, Russel NL, Thompson JE, Warnock TH, Shellshear ID, Buchanan PR. A multicentre comparison of the efficacy of termulticentre comparison of the efficacy of terbutaline Turbuhaler and salbutamol pres-
surised metered dose inhaler in hot humid surised metered dose inhaler in hot

44 regions. Eur Respir F 1994; 7: 342-5. Selross D, Lofroos A-B, Pietinalho A, Riska $\mathrm{H}$.
Comparison of terbutaline and placebo from a pressurised metered dose inhaler and a dry powder inhaler in a subgroup of patients with asthma. Thorax 1994; 49: 1228-30.

45 Clay MM, Pavia D, Newman SP, Clarke SW. Factors influencing the size distribution of aerosols from jet nebulizers. Thorax 1983; 38: $755-9$.

46 Kendrick AH, Smith EC, Denyar J. Nebulizers - fill volume, residual volume and matching of nebulizer to compressor. (editorial) Respir Med 1995; 89: 157-9.

47 Mercer TT. Production of therapeutic aerosols: principles and techniques. Chest 1981;80: 813-8.

48 Lewis RA, Ellis CJ, Fleming JS, Balachandran W. Ultrasonic and jet nebulizers: differences in their physical properties and fractional deposition and the airway response to nebulized water and saline solutions. Thorax 1984; 39: 712

49 Ryan G, Dolovich MB, Obminiski G, et al. Standardisation of inhalation provocation tests. $\mathcal{f}$ Allergy Clin Immunol 1981; 67: 156-61.

50 Clay MM, Clarke SW. Wastage of drugs from nebulizers :a review. $f R$ Soc Med 1987; 80: 38-9.

51 Knoch M, Wunderlich E, Geldner S. A nebulizer system for highly reproducible aerosol delivery. F Aerosol Med 1994; 7: 229-37.
52 Newham DM, Lipworth BJ. Nebulizer performance, pharmacokinetics, airways and systemic effects of salbutamol given via a novel nebulizer delivery system ('Ventstream') Thorax 1994; 49: $762-70$.

53 Kraemer R, Birrer P, Modelska K, Aebischer $\mathrm{CC}$, Schoni MH. A new baby-spacer device for eC, Schoni MH. A new baby-spacer device for infants with bronchopulmonary disease. Eur $\mathcal{f}$ infants with bronchopulmon

54 Chege JK, Chrystyn H. Volumatic usage: some generic salbutamol metered dose inhalers can be used. Thorax 1994; 49: 1162-3.

55 Newman SP. Generic salbutamol metered dose inhalers (letter). Thorax 1995; 50: 590.

56 Jäger-Waldua $R$, Mehring $H$, Wiggins JD. A mechanical micro spray pump: an alternative to propellant driven devices? 7 Aerosol Med 1994; 7: $189-96$.

57 Zierenburg B. The Respimat, a new inhalation system based on the piezoelectric effect. $\mathcal{F}$ Biopharmaceut Sci 1992; 3: 85-90.

58 Jäger-Waldau $R$, Mehring $H$, Wiggins JD. Feasibility of a low dosage dynamic powder Feasibility of a low dosage dynamic powder
dispenser for drug delivery to the lungs. $f$ Aerosol Med 1994; 7: 205-8.

59 Schultz RK, Miller NC, Smith DK, Ross RL. Powder aerosols with auxilliary means of dispe sion. F Biopharmaceut Sci 1992; 3: 115-21.

60 Taylor KMG, Newton JM. Liposomes for controlled delivery of drugs to the lung. (editorial) Thorax 1992; 47: 257-9. 